\title{
Reduction of radiation exposure to operating physician and assistant using a real-time auditory feedback dosimeter during femoral artery puncturing: a study on swine model
}

\author{
Muhammad Umair Ahmad Khan ${ }^{1}$ and Byung-Ju $\mathrm{Yi}^{2^{*}}$ (1)
}

\begin{abstract}
Background: Real-time dosimeters may create a relatively safer environment not only for the patient but also for the physician and the assistant as well. We propose the use of a real-time radiation measurement dosimeter having auditory feedback to reduce radiation exposure.

Methods: Radiation dose rates were measured for 30 fluoroscopy-guided puncturing procedures of femoral arteries in swine. Fifteen puncturing procedures were performed with real-time radiation measurement dosimeter having auditory feedback and other 15 were performed without auditory feedback dosimeter by an interventional cardiologist with 10 years of experience.

Results: The left body side of the operating physician $(38 \%, p<0.001)$ and assistant $(25 \%, p<0.001)$ was more exposed as compared to the right body side. Radiation dose rate to the left hand, left arm and left leg were reduced from $0.96 \pm$ 0.10 to $0.79 \pm 0.12 \mathrm{mSv} / \mathrm{h}(17 \%$ reduction, $p<0.001)$, from $0.11 \pm 0.02$ to $0.07 \pm 0.01 \mathrm{mSv} / \mathrm{h}$ ( $36 \%$ reduction, $p<0.001)$ and from $0.22 \pm 0.06$ to $0.15 \pm 0.02 \mathrm{mSv} / \mathrm{h}$ ( $31 \%$ reduction, $p<0.001$ ) with the use of auditory feedback dosimeter, respectively. The mean fluoroscopic time was reduced from $4.8 \pm 0.43 \mathrm{~min}$ to $4.2 \pm 0.53 \mathrm{~min}(p<0.001)$. The success rate of performing arterial puncturing was $100 \%$.

Conclusions: The use of auditory feedback dosimeter resulted in reduction in effective dose. The sound beep alerted the physician from the danger of exposure, and this approach induced awareness and protective mindset to the operating physician and assistant.
\end{abstract}

Keywords: Fluoroscopy, Occupational exposure, Radiation exposure, Radiation protection, Radiometry

\section{Key points}

- Fluoroscopy-guided puncturing of femoral arteries in pigs is performed with $(n=15)$ and without $(n=15)$ a real-time auditory feedback dosimeter

- Radiation dose rate to the left hand of the operating physician was significantly reduced from 0.96 to $0.79 \mathrm{mSv} / \mathrm{h}(-17 \%)$.
- Radiation dose rate to the left arm of the operating physician was significantly reduced from 0.11 to $0.07 \mathrm{mSv} / \mathrm{h}(-36 \%)$.

- Radiation dose rate to the left leg of the operating physician was significantly reduced from 0.22 to $0.15 \mathrm{mSv} / \mathrm{h}(-31 \%)$.

- Fluoroscopy time was significantly reduced from 4.8 to $4.2 \mathrm{~min}$.

\section{Background}

2Department of Electronic Systems Engineering, Hanyang University, 55

Hanyangdeahak-ro, Sangnok-gu, Ansan, Gyeonggi-do 15588, South Korea

Full list of author information is available at the end of the article
Fluoroscopy is commonly used for precisely targeting and placing needles and guidewires during interventional 
procedures. However, it results in radiation exposure for the operating physician (OP), the patient and the medical personnel [1-6]. The continuous exposure of radiation will cause severe damages of biological nature for humans exposed [7, 8].

Complex vascular interventional procedures involve radiation exposure for the $\mathrm{OP}$, patients and the medical staff assisting the physicians [9]. The effective dose rate varies from $\mu \mathrm{Sv}$ to $\mathrm{mSv}$ per procedure. Radiation dose to the OP's hands had been measured in various studies [10-12]. The average value of eye lens dose limit has been reduced to $20 \mathrm{mSv}$ per year for 5 years, without exceeding $50 \mathrm{mSv}$ in a single year [13].

Various techniques have been proposed to reduce the radiation exposure in the operating room, mainly by optimisation of fluoroscopic devices, sometimes reducing the image quality. Of note, proper positioning of $x$-ray source and operating fluoroscopic devices in pulsed mode can significantly reduce radiation [14-16]. Protective shielding is another way to reduce the radiation dose to the medical staff. It includes thyroid collars and lead aprons used as a protection against radiation exposure [17].

The main limitation of thermoluminescence dosimeters is given by the availability of exposure data only at a later stage $[16,18]$. Conversely, real-time radiation dosimetry provides radiation exposure feedback in real-time so that the OP and whole staff can prevent increased exposure by changing position/orientation of the fluoroscopic devices and maintaining a safe distance. Radiation awareness among the medical staff and physicians can be augmented by giving them personalised real-time feedback about the radiation dose, changing the behaviour of the medical staff [19].

In addition, current radiation measurement techniques provide cumulative dose and real-time radiation measurement devices have been proposed but they have the great limitation of being highly expensive [20].

In this study, we propose a cheap and portable radiation measurement technique using real-time radiation measurement dosimeter having auditory feedback.

\section{Methods}

This study was approved by the Animal Ethical Committee of Seoul National University Bundang Hospital (code of approval: BA1708-230/075-01). The procedures were performed in accordance with the Guide for the Care and Use of Laboratory Animals from the Institute of Laboratory Animals Resources [21].

\section{Animal preparation}

The day before the experiment, male crossbred swine ( $n=15$; weight, from 17 to $35 \mathrm{~kg}$ ) were fed with aspirin $(300 \mathrm{mg})$ and clopidogrel $(300 \mathrm{mg})$. On the experiment day, the swine were premedicated with atropine sulfate
$(0.05 \mathrm{mg} / \mathrm{kg}$, intramuscularly) and subsequently anaesthetised with Zoletil $(5 \mathrm{mg} / \mathrm{kg})$ and Xylazine $(4.4 \mathrm{mg} / \mathrm{kg})$ intramuscularly, intubated and ventilated with room air and isoflurane. We inserted a 6-Fr sheath via the right carotid artery by ultrasound-guided puncture. The animals received heparin $(5000 \mathrm{U})$ intravenously prior to femoral artery digital subtraction angiography.

\section{Real-time radiation measuring device}

A real-time radiation measuring dosimeter (Ray 3000, Kedian, Jining, China) with auditory feedback was used to measure the radiation dose rates (Fig. 1). It can measure the radiation dose rate ranges from $0.01 \mu \mathrm{Sv} / \mathrm{h}$ to $99.99 \mathrm{mSv} / \mathrm{h}$. It has five threshold alarm settings $(0.5,1$, $2.5,10,30,50 \mu \mathrm{Sv} / \mathrm{h})$. Alarm type can be set either pulsed, continuous or silent. The device was set at 10 $\mu \mathrm{Sv} / \mathrm{h}$ as the threshold value.

\section{Fluoroscopy-guided arterial puncture}

A total of 30 fluoroscopy-guided punctures were performed, 15 using the real-time radiation measurement dosimeter with auditory feedback and 15 without auditory feedback dosimeter (the dosimeter was set in silent mode) by an interventional cardiologist with 10 -year experience, targeting both femoral arteries in the 15 pigs. The mobile fluoroscopy system was Philips BV Pulsera (Philips Medical Systems, Bothell, USA). We selected both femoral arteries with a diagnostic catheter (Judkins right 4, Gifu, Japan) via the right carotid artery and performed angiography to guide the femoral puncture using the Seldinger technique.

\section{Measurement of radiation dose and fluoroscopic time}

In each case, the OP wore the dosimeters at three different positions, attached to hands, arms, and legs of the physician and the assistant in order to measure the radiation dose rate as shown in Fig. 2 and Fig. 3, respectively. All the dose rates were measured in millisievert per hour. Mean fluoroscopic time had also been measured with and without auditory feedback dosimeter.

\section{Position of physician and C-arm in the operating theatre}

In clinical practice, when performing fluoroscopy, two positions of the $\mathrm{C}$-arm are commonly adopted. In these positions, either left or right body side of the OP is more exposed as compared to the other. In this study, the $\mathrm{C}$-arm was positioned such that the left body side of the OP and the assistant was more exposed as compared to the right body side. The distance between the unprotected parts of $\mathrm{OP}$ and the swine varied depending upon the position and orientation of the OP. The hands, legs, and arms were the unprotected parts of the body and the distance was not constant, varying as the OP changes the position. However, the range of the arm distance from the swine was about 20 to 


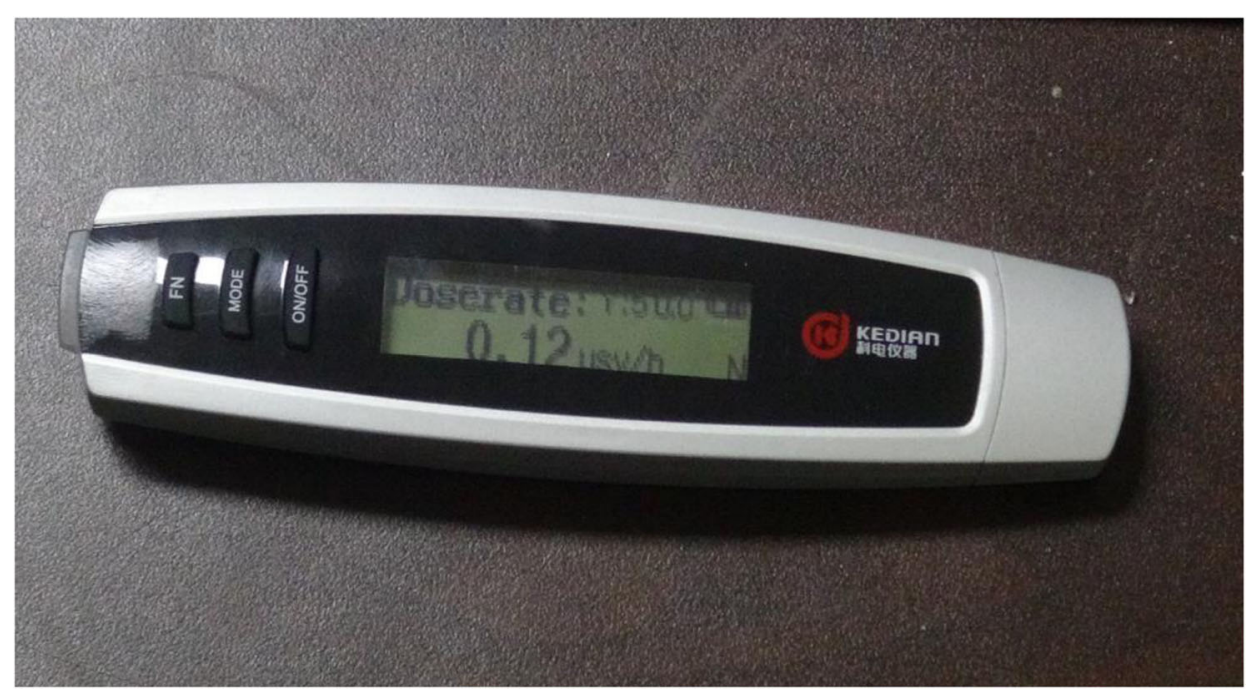

Fig. 1 X-ray dosimeter Ray 3000. It measures the radiation dose rates in millisievert per hour and microsievert per hour

$30 \mathrm{~cm}$ and the range of the leg distance from the swine was about 40 to $50 \mathrm{~cm}$. The distance between the $\mathrm{x}$-ray source and the swine was about $80 \mathrm{~cm}$ and the distance between the intensifier and the swine was about $30 \mathrm{~cm}$.

\section{Statistical analysis}

Continuous variables were reported as mean \pm standard deviation, taking into consideration their normal or nearnormal distribution, confirmed by Shapiro-Wilk test $(p=0.880)$. As a consequence, the comparison between the means of the two groups was evaluated by Student $t$ test. A two-sided probability value of $<0.05$ was considered indicative of a statistically significant difference. The success rates were presented as percentages with their $95 \%$ confidence intervals, calculated according to the binomial distribution. Statistical analysis was performed using $\mathrm{R}$ programme version 3.1.0 (The R Foundation, Vienna, Austria).

\section{Results}

The success rate of performing arterial puncturing was $15 / 15$ (100\%, 95\% confidence interval 0.78-1.00), both with or and without auditory feedback dosimeter. Table 1 shows the radiation dose rate for the $\mathrm{OP}$ and the assistant. The mean values of radiation dose rates for the left and right hand were $0.96 \mathrm{mSv} / \mathrm{h}$ and $0.74 \mathrm{mSv} / \mathrm{h}$, respectively. Similarly, the mean values of radiation dose rates for the left arm and left leg were $0.11 \mathrm{mSv} / \mathrm{h}$ and $0.35 \mathrm{mSv} / \mathrm{h}$, respectively.

The radiation exposure of assistant was significantly $(-90 \%, p<0.001)$ lower as compared to the OP. The left side of the assistant was more exposed as compared to the right side. The mean values of radiation dose rates for the left and right hand were $0.10 \mathrm{mSv} / \mathrm{h}$ and $0.06 \mathrm{mSv} / \mathrm{h}$, respectively. Similarly, the mean values of radiation dose rates for the left arm and left leg were $0.05 \mathrm{mSv} / \mathrm{h}$ and $0.04 \mathrm{mSv} / \mathrm{h}$, respectively.

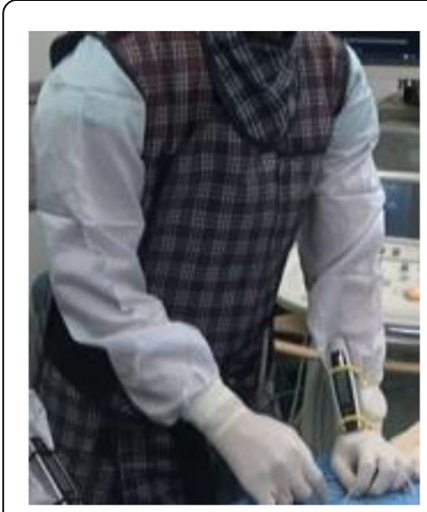

a

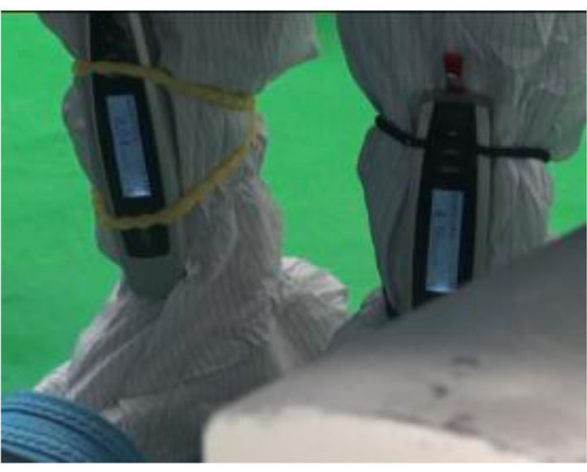

b

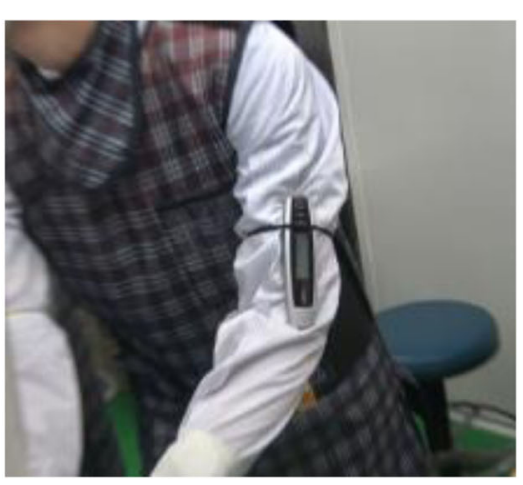

C

Fig. $\mathbf{2}$ Location of dosimeter for the operating physician. The dosimeter is attached to various unprotected body parts of the operating physician to measure radiation dose rates: $\mathbf{a}$ hands, $\mathbf{b}$ legs, $\mathbf{c}$ arms 


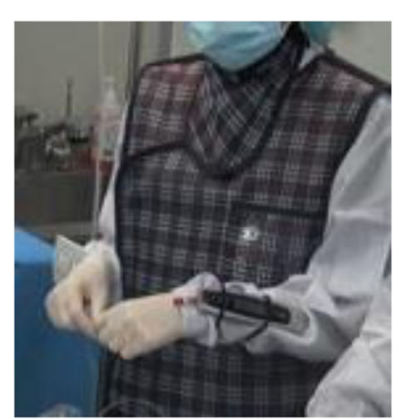

a

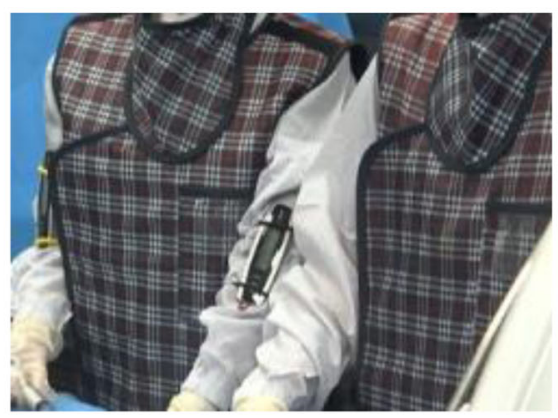

b

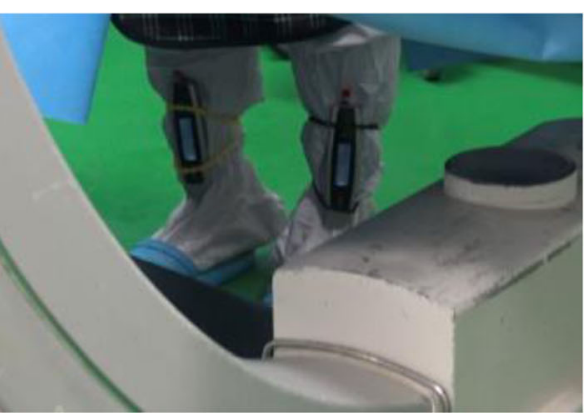

C

Fig. 3 Location of dosimeter for the assistant. The dosimeter is attached to various unprotected body parts of the assistant to measure radiation dose rates: a hands, $\mathbf{b}$ arms, $\mathbf{c}$ legs

Table 2 shows the mean fluoroscopic exposure time and radiation dose rate for the left hand, arm and leg with and without using dosimeter having auditory feedback. It was reduced from 4.8 to $4.2 \mathrm{~min}$ with the use of auditory feedback dosimeter. The mean value of radiation dose rate to left hand, left arm and left leg had been reduced from $0.96 \pm 0.10$ to $0.79 \pm 0.12 \mathrm{mSv} / \mathrm{h}, 0.11 \pm 0.02 \mathrm{mSv} / \mathrm{h}$ without the use of auditory feedback dosimeter to $0.07 \pm 0.01 \mathrm{mSv} / \mathrm{h}$ and $0.22 \pm 0.06$ to $0.15 \pm 0.02$, respectively, with the use of auditory feedback dosimeter.

\section{Discussion}

The objective of the study was the use of real-time radiation dosimeter having auditory feedback to reduce radiation exposure for both the OP and the assistant. It was found that the OP was significantly more exposed as compared to the assistant. It was also observed that the left body side of the OP and assistant was significantly more exposed as compared to the right one. With the use of real-time radiation dosimeter having auditory feedback, $17 \%$ decrease in radiation exposure for the left hand, 36\% decrease for the left arm and 31\% decrease for the left leg was observed. The mean fluoroscopy time was slightly by significantly reduced.

Table 1 Radiation dose rate (mSv/h) for the operating physician and the assistant

\begin{tabular}{|c|c|c|c|c|c|c|}
\hline & $\begin{array}{l}\text { Left } \\
\text { hand } \\
(n=15)\end{array}$ & $\begin{array}{l}\text { Right } \\
\text { hand } \\
(n=15)\end{array}$ & $\begin{array}{l}\text { Left leg } \\
(n=15)\end{array}$ & $\begin{array}{l}\text { Right } \\
\text { leg } \\
(n=15)\end{array}$ & $\begin{array}{l}\text { Left } \\
\text { arm } \\
(n=15)\end{array}$ & $\begin{array}{l}\text { Right } \\
\text { arm } \\
(n=15)\end{array}$ \\
\hline $\begin{array}{l}\text { Dose rate for } \\
\text { the operating } \\
\text { physician } \\
\text { (mean } \pm \text { SD) }\end{array}$ & $\begin{array}{l}0.960 \pm \\
0.100\end{array}$ & $\begin{array}{l}0.740 \pm \\
0.190\end{array}$ & $\begin{array}{l}0.220 \pm \\
0.060\end{array}$ & $\begin{array}{l}0.140 \pm \\
0.030\end{array}$ & $\begin{array}{l}0.110 \pm \\
0.020\end{array}$ & $\begin{array}{l}0.060 \pm \\
0.010\end{array}$ \\
\hline$p$-value & \multicolumn{2}{|c|}{$<0.001$} & \multicolumn{2}{|c|}{$<0.001$} & \multicolumn{2}{|c|}{$<0.001$} \\
\hline $\begin{array}{l}\text { Dose rate for } \\
\text { the assistant } \\
\text { (mean } \pm \mathrm{SD})\end{array}$ & $\begin{array}{l}0.090 \pm \\
0.010\end{array}$ & $\begin{array}{l}0.070 \pm \\
0.010\end{array}$ & $\begin{array}{l}0.020 \pm \\
0.010\end{array}$ & $\begin{array}{l}0.010 \pm \\
0.004\end{array}$ & $\begin{array}{l}0.030 \pm \\
0.010\end{array}$ & $\begin{array}{l}0.010 \pm \\
0.003\end{array}$ \\
\hline$p$-value & \multicolumn{2}{|c|}{$<0.001$} & \multicolumn{2}{|c|}{$<0.001$} & \multicolumn{2}{|c|}{$<0.001$} \\
\hline
\end{tabular}

$S D$ Standard deviation
Notably, the real-time radiation measurement dosimeter Ray 3000 with auditory feedback is not only cheap but also portable, being easily attachable to various body parts. The beep sound warning system based on auditory feedback allowed the operator and assistant to modify their behaviour to reduce radiation exposure and this approach helped in creating awareness among themselves. The use of the auditory feedback dosimeter allowed the OP to perform arterial puncturing with less exposure. In fact, when the OP and assistant did not wear dosimeters, they moved closer to the $x$-ray source in order to properly utilise the workspace. As a result, their bodies were more exposed to radiation. Of note, the effective dose increases with the increase in the weight of the patient [22] and studies have shown that for every $1 \mathrm{~cm}$ of thickness of body tissue, there is a $25 \%$ increase in the radiation exposure for the patient [23].

This technique could help in the reduction of radiation but still had limitations because both the OP and assistant work in close vicinity of the radiation environment. The

Table 2 Fluoroscopic exposure time and radiation dose rates with and without auditory feedback dosimeter

\begin{tabular}{lll}
\hline Parameters & $\begin{array}{l}\text { Without auditory } \\
\text { feedback dosimeter } \\
(n=15)\end{array}$ & $\begin{array}{l}\text { With auditory } \\
\text { feedback dosimeter } \\
(n=15)\end{array}$ \\
\hline $\begin{array}{l}\text { Fluoroscopic exposure time } \\
\text { (min) (mean } \pm \text { standard } \\
\text { deviation) }\end{array}$ & $4.800 \pm 0.430$ & $4.200 \pm 0.530$ \\
$\begin{array}{l}p \text {-value } \\
\text { Radiation dose rate for the }\end{array}$ & $0.960 \pm 0.100$ & $<0.001$ \\
left hand (mSv/h) & $0.790 \pm 0.120$ \\
$\begin{array}{l}p \text {-value } \\
\text { Radiation dose rate for the } \\
\text { left arm (mSv/h) }\end{array}$ & $0.110 \pm 0.020$ & $0.0070 \pm 0.010$ \\
$p$-value & & $<0.001$ \\
$\begin{array}{l}\text { Radiation dose rate for the } \\
\text { left leg (mSv/h) }\end{array}$ & $0.220 \pm 0.060$ & $0.150 \pm 0.020$ \\
$p$-value & & $<0.001$ \\
\hline
\end{tabular}


use of robotic arterial puncturing mechanisms would allow the OP to perform procedures far from the radiation source so that the OP and assistant would be less exposed to scattered radiation [24]. Such dosimeters having auditory feedback would be used for the extravascular procedure where hand-body exposure is higher than vascular intervention. The other limitation of this study was a small sample size. However, the reduction of radiation for the left body side using auditory feedback dosimeter was significant.

In peripheral intervention, various puncture sites are required other than the femoral or radial artery, such as dorsalis pedis artery, posterior tibial artery, peroneal artery, or even plantar arteries. In those cases, it is hard to identify small arteries using sonography and it is much easier under the guidance of fluoroscopy and contrast angiography. The reason for more time consumption in arterial puncturing was the complications related to smaller arterial size in animal models and higher susceptibility of the arterial wall to complications. In the presence of human patients, real-time radiation dosimeter technique would be effective since the dosimeter has three alarm settings: pulsed, continuous and silent. In both pulsed and continuous case, the sound of the alarm is low as compared to the sound beep of the switching on of the fluoroscopic C-arm so this dosimeter would not disturb the patient.

In conclusion, the use of real-time radiation measurement dosimeter having auditory feedback had created awareness about the risk of exposure and significantly reduced radiation dose rates for the hands, arms and legs. The use of this technique would eventually lead us towards a safer environment not only for the patient but also for the OP and the medical staff.

\section{Abbreviations}

OP: Operating physician

\section{Acknowledgements \\ This work was supported by the Technology Innovation Program (or Industrial Strategic Technology Development Program-Artificial intelligence bio-robot medical convergence project) (20001257, Artificial intelligence algorithm based vascular intervention robot system for reducing radiation exposure and achieving $0.5 \mathrm{~mm}$ accuracy) funded by the Ministry of Trade, Industry \& Energy (MOTIE, Korea), the Ministry of Health \& Welfare (MOHW), Ministry of Science and ICT (MSIT), Korea Evaluation Institute of Industrial Technology (KEIT), supported by the Technology Innovation Program (10052980, Development of microrobotic system for surgical treatment of chronic total occlusion) funded by the Ministry of Trade, Industry \& Energy, Korea, and supported by the BK21 Plus Program funded by National Research Foundation of Korea (NRF).}

\section{Authors' contributions}

All authors read and approved the final manuscript. The first author collected the data. Both the first author and corresponding author contributed in writing the manuscript.

\section{Funding}

This work was supported by the Technology Innovation Program (or Industrial Strategic Technology Development Program-Artificial intelligence bio-robot medical convergence project) (20001257, Artificial intelligence algorithm based vascular intervention robot system for reducing radiation exposure and achieving $0.5 \mathrm{~mm}$ accuracy) funded by the Ministry of Trade, Industry \& Energy (MOTIE, Korea), the Ministry of Health \& Welfare (MOHW), Ministry of Science and ICT (MSIT), Korea Evaluation Institute of Industrial Technology (KEIT), supported by the Technology Innovation Program (10052980, Development of microrobotic system for surgical treatment of chronic total occlusion) funded by the Ministry of Trade, Industry \& Energy, Korea, and supported by the BK21 Plus Program funded by National Research Foundation of Korea (NRF).

\section{Availability of data and materials}

Individual measurement data are available on reasonable request.

\section{Ethics approval and consent to participate}

This study was approved by the Animal Ethical Committee of Seoul National University Bundang Hospital and was performed in accordance with the Guide for the Care and Use of Laboratory Animals from the Institute of Laboratory Animals Resources.

\section{Consent for publication}

Not applicable

\section{Competing interests}

The authors declare that they have no competing interests.

\section{Author details}

${ }^{1}$ Department of Mechatronics Engineering, Hanyang University, Ansan, Gyeonggi-do, South Korea. 'Department of Electronic Systems Engineering, Hanyang University, 55 Hanyangdeahak-ro, Sangnok-gu, Ansan, Gyeonggi-do 15588, South Korea.

Received: 18 April 2019 Accepted: 24 July 2019

Published online: 23 September 2019

\section{References}

1. Balter S, Miller DL (2014) Patient skin reactions from interventional fluoroscopy procedures. AJR Am J Roentgenol 202:W335-W342. https://doi. org/10.2214/AJR.13.12029

2. Miller DL, Balter S, Cole PE et al (2003) Radiation doses in interventional radiology procedures: the RAD-IR study part II: skin dose. J Vasc Interv Radiol 14:977-990. https://doi.org/10.1097/01.RVI.0000084601.43811.CB

3. Tzanis E, Tsetis D, Kehagias E, loannou CV, Damilakis J (2019) Occupational exposure during endovascular aneurysm repair (EVAR) and aortoiliac percutaneous transluminal angioplasty (PTA) procedures. Radiol Med:1-7. https://doi.org/10.1007/s11547-018-00985-8

4. Kim KP, Miller DL, Berrington de Gonzalez A et al (2012) Occupational radiation doses to operators performing fluoroscopically-guided procedures. Health Phys 103:80. https://doi.org/10.1097/HP.0b013e31824dae76

5. Miraglia R, Gerasia R, Maruzzelli L, D’Amico M, Luca A (2017) Radiation doses to operators performing transjugular intrahepatic portosystemic shunt using a flat-panel detector-based system and ultrasound guidance for portal vein targeting. Eur Radiol 27:1783-1786. https://doi.org/10.1007/s00330-016-4558-1

6. Chida K, Kaga Y, Haga Y et al (2013) Occupational dose in interventional radiology procedures. AJR Am J Roentgenol 200:138-141. https://doi.org/1 $0.2214 /$ AJR.11.8455

7. Ko S, Chung HH, Cho SB et al (2017) Occupational radiation exposure and its health effects on interventional medical workers: study protocol for a prospective cohort study. BMJ open 7:e018333. https://doi.org/10.1136/ bmjopen-2017-018333

8. Mercuri M, Sheth T, Natarajan MK (2011) Radiation exposure from medical imaging: a silent harm? CMAJ 183:413-414. https://doi.org/10.1503/cmaj.101885

9. Mahajan A, Samuel S, Saran AK, Mahajan MK, Mam MK (2015) Occupational radiation exposure from $C$ arm fluoroscopy during common orthopaedic surgical procedures and its prevention. J Clin Diagn Res: JCDR 9:RC01. https://doi.org/10.7860/JCDR/2015/10520.5672

10. Krim S, Brodecki M, Carinou E et al (2011) Extremity doses of medical staff involved in interventional radiology and cardiology: correlations and annual doses (hands and legs). Radiat Meas 46:1223-1227. https://doi.org/10.1016/j. radmeas.2011.07.010 
11. Vosbikian MM, llyas AM, Watson DD, Leinberry CF (2014) Radiation exposure to hand surgeons' hands: a practical comparison of large and mini C-arm fluoroscopy. J Hand Surg Am 39:1805-1809. https://doi.org/10.1016/j.jhsa.2 014.06 .133

12. Singer $G$ (2005) Radiation exposure to the hands from mini $C$-arm fluoroscopy. J Hand Surg Am 30:795-797. https://doi.org/10.1016/j. jhsa.2005.01.007

13. Cantone MC, Ginjaume M, Miljanic S et al (2017) Report of IRPA task group on the impact of the eye lens dose limits. J Radiol Prot 37:527. https://doi. org/10.1088/1361-6498/aa604b

14. Narain AS, Hijji FY, Yom KH, Kudaravalli KT, Haws BE, Singh K (2017) Radiation exposure and reduction in the operating room: perspectives and future directions in spine surgery. World J Orthop 8:524. https://doi.org/1 0.5312/wjo.v8.17.524

15. Meisinger QC, Stahl CM, Andre MP, Kinney TB, Newton IG (2016) Radiation protection for the fluoroscopy operator and staff. AJR Am J Roentgenol 207: 745-754. https://doi.org/10.2214/AJR.16.16556

16. Werner GS, Glaser P, Coenen A et al (2017) Reduction of radiation exposure during complex interventions for chronic total coronary occlusions: implementing low dose radiation protocols without affecting procedural success rates. Catheter Cardiovasc Interv 89:1005-1012. https://doi.org/10.1 $002 / c c d .26886$

17. Gonzales JP, Moran C, Silberzweig JE (2014) Reduction of operator radiation dose by an extended lower body shield. J Vasc Interv Radiol 25:462-468. e461. https://doi.org/10.1016/j.jvir.2013.11.006

18. Müller M, Strauss A, Pflugmacher $R$ et al (2014) Evaluation of radiation exposure of personnel in an orthopaedic and trauma operation theatre using the new real-time dosimetry system "dose aware". Z Orthop Unfall 152:381-388. https://doi.org/10.1055/s-0034-1368603

19. Sailer $A M$, Vergoossen $L$, Paulis $L$ et al (2017) Personalized feedback on staff dose in fluoroscopy-guided interventions: a new era in radiation dose monitoring. Cardiovasc Intervent Radiol 40:1756-1762. https://doi.org/10.1 007/s00270-017-1690-5

20. Inaba Y, Chida K, Kobayashi R, Kaga Y, Zuguchi M (2014) Fundamental study of a real-time occupational dosimetry system for interventional radiology staff. J Radiol Prot 34:N65. https://doi.org/10.1088/0952-4746/34/3/N65

21. Institute of Laboratory Animal Resources (U.S.) Committee on Care and Use of Laboratory Animals, National Institutes of Health (U.S.) Division of Research Resources (1985) Guide for the care and use of laboratory animals. U.S. Dept. of Health and Human Services, Public Health Service, National Insititutes of Health, Bethesda

22. Yanch JC, Behrman RH, Hendricks MJ, McCall JH (2009) Increased radiation dose to overweight and obese patients from radiographic examinations. Radiology 252:128-139. https://doi.org/10.1148/radiol.2521080141

23. Gurley JC (2009) Flat detectors and new aspects of radiation safety. Cardio Clin 27:385-394. https://doi.org/10.1016/j.ccl.2009.04.004

24. Khan MUA, Yoon CH, Yi BJ (2019) Reduction of operator radiation exposure using a passive robotic device during fluoroscopy-guided arterial puncture: an experimental study in a swine model. Eur Radiol Exp 3:20. https://doi. org/10.1186/s41747-019-0098-1

\section{Publisher's Note}

Springer Nature remains neutral with regard to jurisdictional claims in published maps and institutional affiliations.

\section{Submit your manuscript to a SpringerOpen ${ }^{\circ}$ journal and benefit from:}

- Convenient online submission

- Rigorous peer review

- Open access: articles freely available online

- High visibility within the field

- Retaining the copyright to your article

Submit your next manuscript at $\boldsymbol{\nabla}$ springeropen.com 